\title{
AC 2011-1118: ASSESSING FIRST-YEAR CALCULUS KNOWLEDGE AND SKILLS NEEDED FOR A SOPHOMORE STATICS AND DYNAMICS COURSE
}

\section{Kristi J Shryock, Texas A\&M University}

Kristi J. Shryock is a Lecturer and Director of Undergraduate Programs in the Department of Aerospace Engineering at Texas A\&M University. She received both a B.S. and M.S. in Aerospace Engineering from Texas A\&M and received her Ph.D. in Interdisciplinary Engineering at Texas A\&M in May 2011. Her research work focuses on engineering education.

\section{Prof. arun r srinivasa, Department of Mechanical Engineering, Texas A\&M University}

Prof Srinivasa obtained his undergraduate degree in Mechanical Engineering from IIT Madras in 1986. He subsequently obtained a Ph.D at UC Berkeley and has been a faculty in the mechanical Engineering Department at Texas A\&M University. He is one of the curriculum coordinators for the freshman engineering program of the Dwight Look College of Engineering at Texas A\&M University, and was also part of the committee that developed the current statics and dynamics class for the Department of Mechanical Engineering

\section{Jefferey E. Froyd, Texas A\&M University}

Jeffrey E. Froyd is the Director of Faculty Climate and Development at Texas A\&M University. He served as Project Director for the Foundation Coalition, an NSF Engineering Education Coalition in which six institutions systematically renewed, assessed, and institutionalized their undergraduate engineering curricula, and extensively shared their results with the engineering education community. He co-created the Integrated, First-Year Curriculum in Science, Engineering and Mathematics at Rose-Hulman Institute of Technology, which was recognized in 1997 with a Hesburgh Award Certificate of Excellence. He has authored or co-authored over 70 papers on engineering education in areas ranging from curricular change to faculty development. He is collaborating on NSF-supported projects for (i) renewal of the mechanics of materials course, (ii) improving preparation of students for Calculus I, (iii) systemic application of concept inventories. He is currently an ABET Program Evaluator and a Senior Associate Editor for the Journal on Engineering Education. 


\title{
Assessing First-year Calculus Knowledge and Skills needed for a Sophomore Statics and Dynamics Course
}

\begin{abstract}
Anecdotally, engineering faculty members complain that students taking sophomore engineering science courses are not prepared with respect to mathematics. However, evidence has rarely been systematically collected and analyzed to determine the veracity of these assertions. More specifically, the intent of the paper is to address two questions:

- With respect to mathematics knowledge and skill, what do engineering faculty members expect students to know and be able to do when they begin a sophomore statics and dynamics course?

- To what extent do students satisfy these expectations?
\end{abstract}

To begin to address these questions, the following steps were taken. First, engineering faculty members who taught a sophomore statics and dynamics course at Texas A\&M University (TAMU) were asked for problems involving first-year calculus and mathematics that they thought students should be able to solve when they entered this course. For each problem, one or more learning outcomes were abstracted. Given the set of learning outcomes engineering faculty members expected students to be able to perform, a set of nine problems was generated to be given to students near the beginning of the statics and dynamics course. The instrument has been administered to a set of students who took the course summer 2010 as well as a set of students who took the course in fall 2010. The paper will describe:

- Some of the problems that were submitted by engineering faculty members

- The set of learning outcomes that was generated

- The pre-course assessment instrument for mathematical knowledge and skills that was generated, and

- Results from over 350 students who took the pre-test.

After administering the instrument and analyzing the results, faculty members have a better idea of the background of their students and can adjust course content. Further, there will be evidence to examine the extent to which students are prepared in mathematics to begin a core engineering science course. Finally, the paper will also present changes that some faculty members made in the course plans to apply what they learned about the extent of their students' mathematics preparation near the beginning of the course.

\section{Introduction}

Mathematics and science are vital parts of an engineering curriculum as evident by the requirements of $\mathrm{ABET}^{1}$. ABET Engineering Criteria require that at least twenty-five percent of the credits for an engineering program be taken in mathematics and science courses. At least one study $^{2}$ has shown that success in the first mathematics course is useful in predicting persistence in an engineering program. While the importance of mathematics for success in studying engineering is unquestioned, deeper understanding of both how engineering faculty members expect their students to apply mathematics and the extent to which engineering students are 
prepared to satisfy the expectations of their faculty members is required. Therefore, the paper intends to address two questions:

- With respect to mathematics knowledge and skill, what do engineering faculty members expect students to know and be able to do when they begin a sophomore statics and dynamics course?

- To what extent do students satisfy these expectations?

\section{Background}

Evaluating how mathematics from the first year is used downstream in the engineering curriculum is not new. In 1974, the Committee on Curricular Emphasis in Basic Mechanics (CCEBM) was formed out of concern within the Mechanics Division of ASEE for the quality of instruction in basic mechanics. This led to the development of an extensive national survey and preparation of a readiness skills test for students entering their first engineering mechanics course $^{3}$. The test focused on providing "hard" data for proper discussions on the emphasis and coverage of basic mathematic skills that are prerequisites to mechanics. It consisted of questions related to both pre-college and college-level mathematics that serve as prerequisites to the mechanics course. Given on a trial run to a few institutions in 1976 and then nationally to 9,500 students from 37 four-year engineering schools and 11 junior colleges and engineering technology programs in 1977, it provided convincing evidence of the lack of mathematics preparation students bring into the mechanics curriculum ${ }^{4}$. Students received an average of 12.8 correct responses out of a total of 25 questions $^{3}$. The test was revisited in 1987 and given to 3,850 students from 21 participating schools to see if any significant changes had occurred ${ }^{5}$. The exact same version of the test was administered, so direct comparisons could be made. While the average number of correct responses did increase to 13.7 in 1987, closer inspection of the data actually showed a wider spread between schools participating. Snyder" noted that "The pressures to maintain enrollments may have softened the entrance requirements in some institutions" (p. 1346). In either administration, an average score of 55\% was considered much lower than the expected average score of $75 \%$. Snyder also stated in his 1988 review that, "The dismal results on this test substantiate the allegations that our students as a group are seriously deficient in their understanding and ability to use even elementary tools of mathematics...It is no wonder that students have difficulty learning mechanics in our basic courses; they have to spend much of their time relearning elementary mathematics." (p. 1346) ${ }^{5}$.

Studies such as the ones cited in the preceding paragraph may have contributed to the motivation for the Neal Report ${ }^{6}$, which emphasized the need for postsecondary institutions to reform undergraduate science, technology, engineering, and mathematics (STEM) education. In a recent study by the Mathematics Association of America (MAA), mathematicians, who led the study, brought together groups of engineering and computer faculty members as well as other downstream consumers, students who took mathematics courses, to explore the evolution or in some cases lack thereof of new instructional practices ${ }^{7}$. Summarizing conversations of the different disciplinary faculty, Ganter and Barker ${ }^{7}$ reported concerns about the mathematics preparation of undergraduate students for their disciplinary courses.

Stimulated by the Neal Report and the willingness of the Federal Government to support National Science Foundation (NSF) grants for innovation in undergraduate STEM education, 
NSF initiated several major initiatives to promote new STEM curricula. One initiative was the Calculus Reform Movement ${ }^{8}$. According to studies funded during the movement, students felt more positive about calculus and perceived they were better prepared ${ }^{9,10,11,12}$. However, little data has been generated to support assertions that reform efforts have had a significant impact on downstream engineering courses ${ }^{13,14}$. Manseur, Ieta, and Manseur ${ }^{15}$ reported that little progress has been made in mathematics education in engineering. They admitted that teaching needs to be different, but they were not sure how to accomplish this. "Furthermore, engineering faculty members still report there are disconnects between the knowledge that students gain in mathematics courses and their ability to apply such knowledge in engineering situations"15.

More recently, there have been several studies completed that assess the mathematics needed for engineering, but it has been from a taxonomy level as opposed to skills based ${ }^{16,17,18}$. For example, in 2007 Cardella's work investigated the mathematical Knowledge Base, Problem Solving Strategies, Use of Resources, Beliefs and Affects, and Practices of students. She looked at the ability of a student to frame problems, apply mathematics to engineering problems, and use software to aid in the learning process ${ }^{16}$. A study by Fadali, Velasquez-Bryant, and Robinson ${ }^{18}$ evaluated the link between attitude and competence in mathematics. They found that, "Most topics in engineering use the language and processes of mathematics as a medium of knowledge representation. It is therefore necessary for students to learn this language to be able to learn engineering problem solving. To state it mathematically, basic skills in mathematics are a necessary, though not sufficient, condition for learning engineering problem solving" (p. F1F$20)^{18}$.

Review of ASEE conference papers published within the last four years suggest that work has still been focusing on first year integration of mathematics with physics and engineering through the use of projects or curriculum incorporation or moving this integration in the sophomore year of curriculum with project-based learning ${ }^{15,19,20}$. Some of the literature is beginning to outline skills from mathematics, but the focus has been on identifying topics from the course and not on the impact on engineering if a student does not possess these skills. For example, Gomes, Bolite, and Powell ${ }^{19}$ looked at assessing the mathematics skills necessary for a final course project. The skills outlined were still framed using the taxonomy level outlined in Cardella's work in $2007^{16}$. Manseur, et al.'s work ${ }^{15}$ addressed the relationship between mathematics and engineering but from a curriculum standpoint. Their work on mathematics preparation viewed it from a curriculum level with an outline of mathematics for curriculum as their final step in their work. Raubenheimer, Ozturk, and Duca ${ }^{20}$ addressed a mechanism to assist students who did not enter an engineering course with the required mathematics skills. Their work focused on a junior-level biomedical engineering course that utilized on-line review materials and a chance for students to test and retest to ensure learning of concepts deemed necessary by the course instructors. While the work briefly discussed that a pre-test covering mathematics skills was given, the main focus on the work was the on-line review modules developed and their impact on a student's learning. No details about specific skills were mentioned.

As shown by the preceding literature review, there have been extensive efforts to:

- Evaluate the preparation, with respect to mathematics, of engineering students for their post-first-year engineering curricula, and

- Reform first-year mathematics courses. 
However, the authors could find no studies that addressed either expectations for mathematical knowledge and skills for specific core engineering courses or the degree to which engineering students beginning a core engineering course satisfied these expectations. Therefore, the authors undertook the study described in the following sections to address the research questions described in the introduction.

\section{Methods}

Selected Course to Analyze

To determine expectations of engineering faculty for the knowledge of mathematics and skill in applying this knowledge that students in their course should have to be successful, the authors identified a core, required, first semester, three credit hour, sophomore-level engineering science course in the mechanical engineering curriculum at TAMU, Statics and Dynamics. One reason this course was selected is because it is also common to many engineering majors at TAMU. In addition, while students complete several engineering courses in their sophomore-year including statics and dynamics, materials, thermodynamics, and numerical methods, the course selected is a statics and dynamics course that resembles many courses in mechanical engineering curricula across the world because it uses material taught in the first-year mathematics and physics mechanics courses and is most directly related and closer in time being at the sophomore-level to the first-year engineering classes. In this course, mechanical engineering students are expected to apply what they learned in their first-year mathematics and calculus-based physics mechanics courses, as well as the mathematics and physics they learned in high school. While other courses in the engineering curriculum utilize mathematics and physics, this course is more directly tied to material covered in the freshman year and is almost considered a gateway course into other engineering courses in the curriculum. As evidence of this, the statics and dynamics course has the most direct follow-on courses for which it is a prerequisite than any other mechanical engineering course in the curriculum. There is a likelihood that students who fail to successfully complete this course will be delayed due to the statics and dynamics course since it is the direct prerequisite for three follow-on courses in the second semester of the sophomore-level curriculum. Taught as a service course in the fall, spring, and summer semesters in the mechanical engineering department, almost 1,000 engineering students per year at TAMU enroll in this particular mechanical engineering three credit hour statics and dynamics course from almost all engineering majors. In addition, since it is taught as a service course for many other departments, the curriculum is common among the different sections of the course, and standardized sets of exams are utilized. For these reasons, it is relatively easy to extract necessary data for comparison. The importance of this course in an engineering curriculum was conveyed by Danielson and Danielson ${ }^{21}$ who determined, "Success in later (sic) courses is directly correlated to success in statics."

\section{Determining Skills}

Next, the authors asked engineering faculty members who teach the course for problems that illustrated the prerequisite mathematics knowledge and skills students should have mastered when they entered the course. The authors thought that asking for problems would be more helpful than asking for a list of topics and getting back a very long list from which it would be 
difficult to construct an instrument to assess student knowledge of these topics. Also, the problems would illustrate contexts into which students would be expected to transfer their mathematical knowledge. Sometimes students may know the mathematical concept or procedures, but they may not recognize that the problem requires what they know because the context of problem is unfamiliar or different than the context in which they learned the concept or procedure. The authors found asking for five problems focused faculty members on their specific expectations for student mathematical knowledge and skills.

After receiving sample problems from five faculty members, the questions were analyzed to develop a set of learning outcomes that would reflect the knowledge and skills required to solve the problems. There was significant overlap among the problems, with respect to the knowledge and skills expected. The resulting set of mathematics topics for which engineering faculty members expected student mastery are listed in Table 1.

\title{
Table 1. First-year Mathematics Topics Determined by Engineering Faculty Members
}

\author{
Projection \\ Vector Components (2-D) \\ Derivative (using Chain Rule) \\ Second Derivative \\ Area Under a Curve \\ Integration (using Substitution) \\ Cross Product (definition) \\ Simultaneous Equations
}

\section{Alpha Instrument}

Using this set of topics and the original problems to guide the authors about the expectations of the engineering faculty members, the authors created a ten-question, alpha version of an instrument to assess student abilities with respect to expectations. The instrument was then reviewed by two of the engineering faculty members who submitted problems, and they agreed the instrument contained the skills necessary to be successful in the course. The authors thought it would take about 30 minutes for students to complete, and the engineering faculty member who taught the statics and dynamics course during the summer of 2010 was willing to allocate 30 minutes of class time to administer the instrument. Also, students were not allowed to use their calculators. Each of the ten questions was multiple choice. For each question, students were given space to work the problems, and the fifth answer on each question was intentionally left as 'none of the above'. It was administered to a group of 37 sophomore-level engineering majors in the course on the second day of class in the summer 2010 semester.

With such a small number of participants, responses could be evaluated for common mistakes to help in the revision process. While the work submitted was anonymous, interested students could include their e-mail address to have a customized report of their work sent to them. The results were then entered into Microsoft Excel and percent correct and incorrect were determined. A summary of the work was then sent to the professor. Instead of simply including percent correct and incorrect or the numbers breakdown by each item, the topics were summarized, and input was provided on where students were generally strong and where students failed to have an 
understanding. Administering the alpha instrument provided an indication of student performance in terms of the expected concepts and skills (see Table 2).

Table 2. Student Performance in terms of Expected Concepts and Skills on Alpha Version

\begin{tabular}{|l|c|c|}
\hline Topic & $\begin{array}{l}\text { Number of Questions on the } \\
\text { Instrument Assessing this Topic }\end{array}$ & $\begin{array}{l}\text { Percentage of Students that } \\
\text { got all of these Questions } \\
\text { Correct }\end{array}$ \\
\hline Projection & 1 & 15 \\
\hline Vector Components (2-D) & 1 & 77 \\
\hline $\begin{array}{l}\text { Derivative (using Chain } \\
\text { Rule) }\end{array}$ & 2 & 27 \\
\hline Second Derivative & 1 & 62 \\
\hline Area Under a Curve & 1 & 41 \\
\hline $\begin{array}{l}\text { Integration (using } \\
\text { Substitution) }\end{array}$ & 2 & 0 \\
\hline Cross Product (definition) & 1 & 74 \\
\hline Simultaneous Equations & 1 & 65 \\
\hline
\end{tabular}

After results from the alpha version of the instrument were analyzed, the instrument was then revised. In addition, item responses and work shown from students were evaluated to determine if students properly understood what the question asked of them, how the responses compared to expectations, and appropriate answers to include in the next prototype.

Homework and exam problems were dissected to gauge what knowledge and skills in mathematics were needed to answer the questions. In addition to this analysis, two doctoral students in mechanical engineering analyzed a set of randomly selected problems to provide a check of the validity of the analysis. Analyzing homework and exam problems allowed the analysis to be based on actual evidence from an offering of the course instead of perceptions faculty members might have about what they wanted. From this analysis, a list of knowledge and skills in mathematics was compared to the original list ${ }^{22}$. After further review, it was determined that projection was not an essential skill for work completed by students in the statics and dynamics course. While it was definitely a tool that could be used, students were not explicitly asked to use it, based on the homework and exam problems. Based on this analysis, additional skills were identified as not greatly used in the course for similar reasons, including integrals using trigonometry substitution and definition of cross product. On the other hand, the process brought to light that three-dimensional vector components and simultaneous equations with a parameter had not been included, and several of the problems related to these skills. Therefore, they were added to the list of skills. The revised instrument was then reviewed by the engineering faculty members who submitted problems and other instructors teaching the same or similar course, and they agreed the instrument contained the skills necessary to be successful in the course. The resulting set of mathematics topics identified as necessary for student mastery are listed in Figure 1. In addition, the comparison between percentage of homework and exam problems covering the topics, percentage of time spent in first-year calculus courses on the topics according to the course syllabi, and percentage of questions pertaining to each topic on the beta version of the mathematics instrument are detailed in the figure. 
Figure 1. Alignment of First-year Mathematics Topics

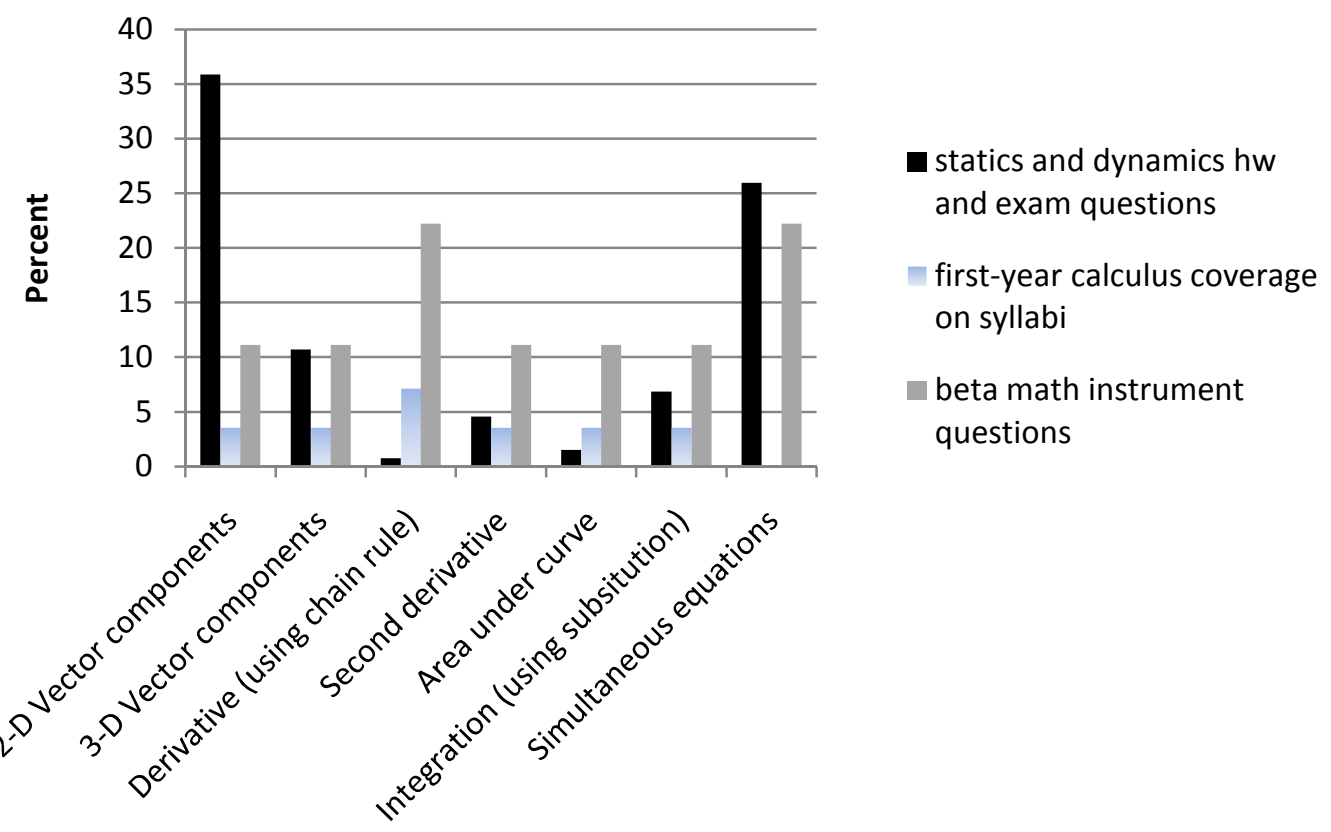

From the figure, serious alignment issues are evident between topics engineering faculty members utilize in the statics and dynamics course and those included in the first-year calculus syllabi. For example, important mathematics skills in the statics and dynamics homework and exam problems include two-dimensional vectors and simultaneous equations. These two topics are briefly covered on the calculus syllabi, if at all.

\section{Beta Instrument}

In fall of 2010, a beta second version of the instrument was given to three sections of the statics and dynamics course whose instructors would allow class time to administer the instrument. There were 271 students who completed the instrument. In addition, the instrument was administered to students in two aerospace engineering courses. The first aerospace course is a two-credit hour course and is equivalent to the first half of the statics and dynamics course, while the second aerospace course is also a two-credit hour course and is equivalent to the second half of statics and dynamics course. These two aerospace engineering courses are taken exclusively by aerospace engineering majors. Including the aerospace students, the total number of students completing the physics instrument was 362 students. As with the alpha version, this instrument was given on the second day of class in the fall semester in each of the sections.

While the plan had been to administer the instrument with scantrons, they were not used for fear of time limitations in the classroom. Therefore, each question was multiple-choice, but students were allowed to denote their answers on each instrument. Students were given 20 minutes to complete the instrument and again were not allowed to use their calculators. Decreasing the amount of class time needed to administer the instrument seemed to make a significant 
difference in the willingness of faculty members to allow class time for the instrument to be administered. The beta version of the mathematics instrument had 9 questions.

Table 3. Student Performance in terms of Expected Concepts and Skills on Beta Version

\begin{tabular}{|l|c|c|}
\hline Topic & $\begin{array}{l}\text { Number of Questions on the } \\
\text { Instrument Assessing this Topic }\end{array}$ & $\begin{array}{l}\text { Percentage of Students that } \\
\text { got all of these Questions } \\
\text { Correct }\end{array}$ \\
\hline Vector Components (2-D) & 1 & 72 \\
\hline Vector Components (3-D) & 1 & 20 \\
\hline $\begin{array}{l}\text { Derivative (using Chain } \\
\text { Rule) }\end{array}$ & 2 & 42 \\
\hline Second Derivative & 1 & 78 \\
\hline Area Under a Curve & 1 & 58 \\
\hline $\begin{array}{l}\text { Integration (using } \\
\text { Substitution) }\end{array}$ & 1 & 33 \\
\hline Simultaneous Equations & 2 & 25 \\
\hline
\end{tabular}

As with the alpha versions, a detailed summary of the results on the topics was sent individually to each faculty member with specific details included on their students. Each student was given the opportunity to receive an individualized personal summary by email.

\section{Results and Discussion}

Once the instrument was administered, results from both the alpha and beta versions were evaluated in more detail. Evaluation, such as item difficulty index, overall results, and results on individual questions were addressed in greater detail.

\section{Alpha Instrument}

The item difficulty index measures the difficulty of a single test question. Calculated by taking the ratio of the number of correct responses on each question to the total number of students who attempted the particular question, the index ranges from 0 to 1 . A larger value for the index signifies that a higher percentage of respondents answered the question correctly, so the item was easier for this population. If the index value is 1 , this signifies that all of the participants answered the question correctly. If the index value is 0 , no one was able to answer the question correctly. Therefore, a value of 0 or 1 does not discriminate very well. While there are a number of different possible criteria for acceptable values of the item difficulty index, a widely adopted criterion requires the value to be between 0.30 and 0.70 within+/-.20 of the optimum value of $0.50^{23}$.

As viewed in Figure 2, the mean difficulty index of the responses in the alpha version of the mathematics instrument given in summer of 2010 is 0.50 . Simply because responses to a question fall outside of the optimum range of 0.30 to 0.70 does not nullify the question, but it does cause concern for closer inspection. The three questions that show warrant for further review are item \#1 with an index value of 0.15 , item \#8 with an index value of 0.09 , and item \#4 
with an index value of 0.94 . Table 4 lists the three questions on the opposing ends of the histogram.

Figure 2. Item Difficulty Index for Alpha Mathematics Instrument

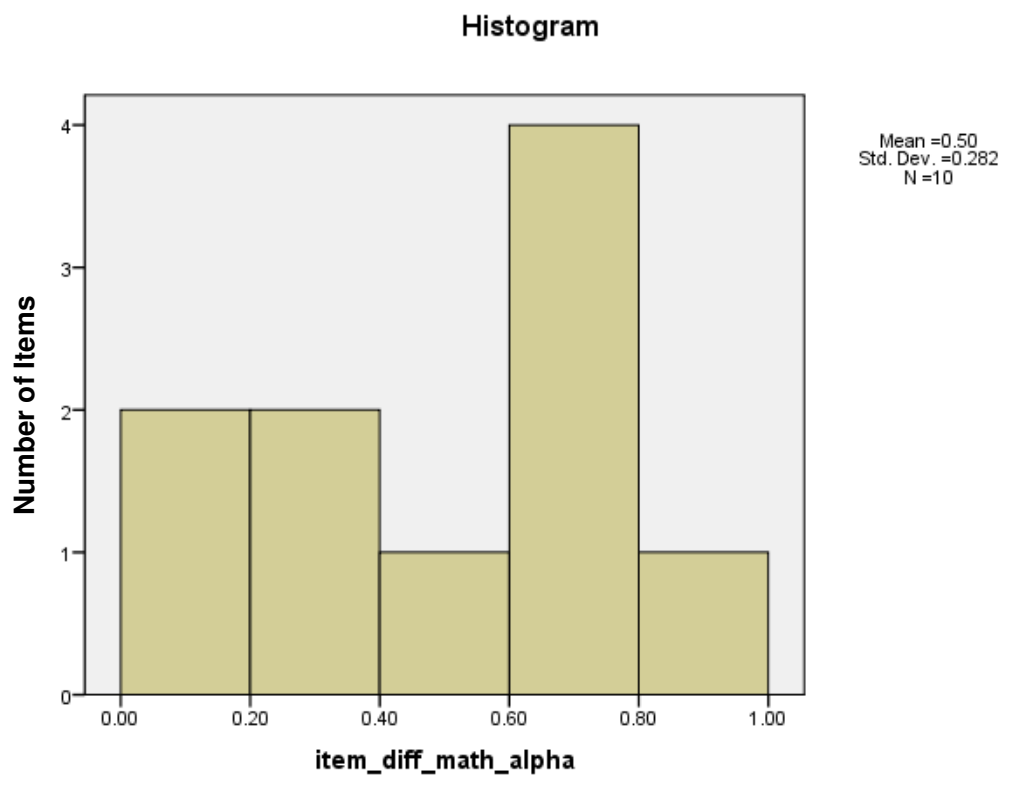

ত
0
$\mathbb{D}$
$\mathbb{D}$
$N$
$N$
$N$
$\mathbb{W}$
$\infty$
$\overrightarrow{0}$ 
Table 4. Questions from Alpha Version of Instrument with Highest and Lowest Item Difficulty Index Value

\begin{tabular}{|c|c|c|c|}
\hline $\begin{array}{c}\text { Question } \\
\#\end{array}$ & $\begin{array}{l}\text { Item } \\
\text { Difficulty } \\
\text { Index } \\
\text { Value }\end{array}$ & Question Statement & Details \\
\hline 8 & 0.09 & $\begin{array}{l}\text { Find an equivalent integral using the } \\
\text { cosine or sine function. } \\
\int \sqrt{16-\mathrm{x}^{2}} d x\end{array}$ & $\begin{array}{l}\text { Students had trouble } \\
\text { solving this problem. } \\
50 \% \text { of the students } \\
\text { answered } 4 \int \cos ^{2} \theta d \theta \text {, } \\
\text { while } 30 \% \\
\text { answered } 4 \int \cos \theta d \theta \text {. }\end{array}$ \\
\hline 1 & 0.15 & $\begin{array}{l}\text { Two vectors are given: } \quad \vec{a}= \\
(-\vec{\imath}+2 \vec{\jmath}) f t \text { and } \vec{b}=(8 \vec{\imath}+ \\
6 \vec{k}) f t \\
\text { What is the projection of } \vec{a} \text { onto the } \\
\text { direction of } \vec{b} \text { ? }\end{array}$ & $\begin{array}{l}\text { Each of the answer } \\
\text { selections had a large } \\
\text { number of responses, } \\
\text { which signified that } \\
\text { students did not know } \\
\text { how to solve this } \\
\text { problem. There was } \\
\text { not a particular } \\
\text { common error. }\end{array}$ \\
\hline 4 & 0.94 & $\begin{array}{l}\text { Find the derivative of the following } \\
\text { function with respect to } t \text {. } \\
\sin \left(2 t^{2}+6\right)\end{array}$ & $\begin{array}{l}\text { Students } \\
\text { overwhelmingly } \\
\text { answered this question } \\
\text { correctly. The largest } \\
\text { error made by } 9 \% \text { of } \\
\text { the students who } \\
\text { answered } 4 t \sin \left(2 t^{2}+\right. \\
6) \text {. }\end{array}$ \\
\hline
\end{tabular}

\section{Beta Instrument}

After minor changes to the alpha version of the instrument, the following results were found in the administration of the second version of the instrument. Figure 3 contains the item difficulty index for the items in the beta mathematics instrument. The range of index values for item difficulty index was pretty uniform with the lowest value obtained on item \#4 with 0.24 and the highest value on item \#3 with 0.81. Table 5 lists the two questions on the opposing ends of the histogram. 
Figure 3. Item Difficulty Index for Beta Mathematics Instrument

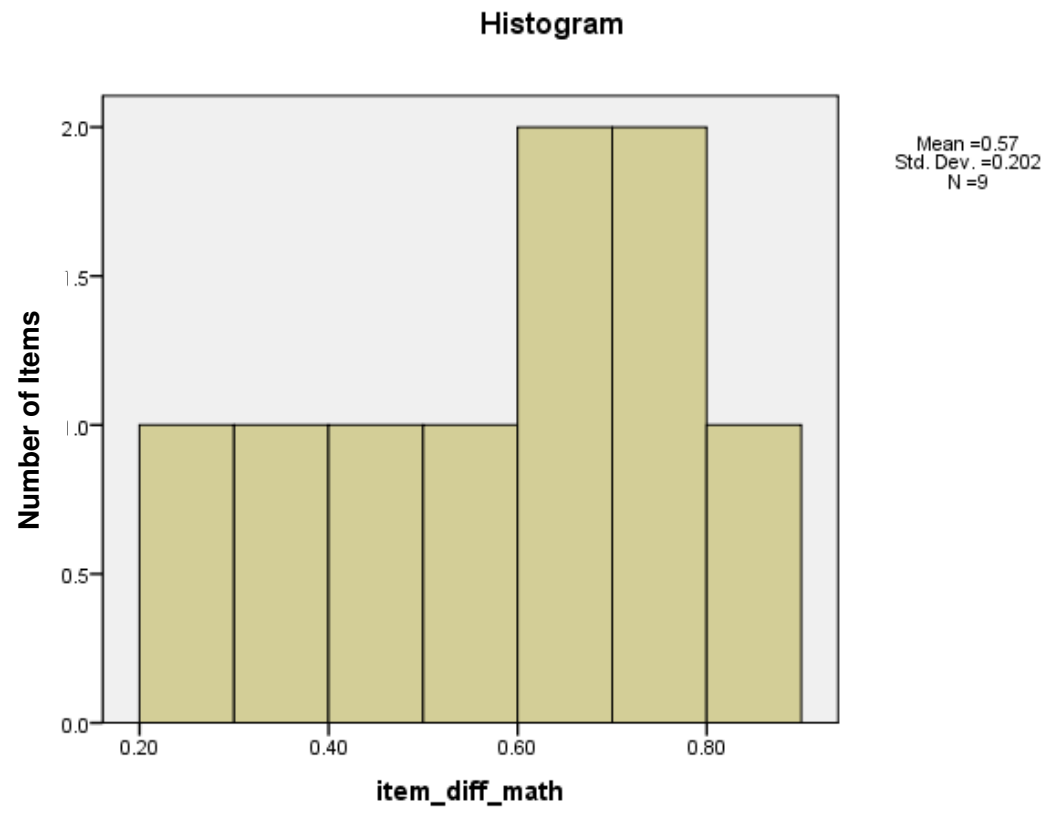

D
0
$\mathbb{D}$
$\mathbb{N}$
$N$
$N$
$\mathbb{W}$
$\infty$
$\vec{N}$ 
Table 5. Questions from Alpha Version of Instrument with Highest and Lowest Item Difficulty Index Value

\begin{tabular}{|c|c|l|l|}
\hline $\begin{array}{c}\text { Question } \\
\#\end{array}$ & $\begin{array}{c}\text { Item } \\
\text { Difficulty } \\
\text { Index } \\
\text { Value }\end{array}$ & \multicolumn{1}{|c|}{ Question Statement } & \multicolumn{1}{|c|}{ Details } \\
\hline 4 & 0.24 & $\begin{array}{l}\text { A heavy sign (not to drawn to scale) } \\
\text { is supported by the following } \\
\text { configuration. What is the } \vec{l} \\
\text { component of the force in cable BC } \\
\text { where } \vec{\imath} \text { is in the positive } x \\
\text { direction? Assume the } \mathrm{F}_{\mathrm{BC}} \text { is a } \\
\text { known force equal to } 500 \mathrm{~N} \text {, and the } \\
\text { force acts along its axis. } \\
\text { (Figure } 4 \text { displays the sign } \\
\text { configuration provided along with the } \\
\text { question.) }\end{array}$ & $\begin{array}{l}\text { Each of the answer } \\
\text { selections had a large } \\
\text { number of responses, } \\
\text { which signified that } \\
\text { students did not know } \\
\text { how to solve this } \\
\text { problem. There was } \\
\text { not a particular } \\
\text { common error. }\end{array}$ \\
\hline 3 & 0.81 & $\begin{array}{l}\text { A point } P \text { travels on a path given by } \\
x(t)=-\frac{1}{6} t^{3} . \text { The term } x \text { is in } \\
\text { meters, and } t \text { is in seconds. Find the } \\
\text { acceleration. }\end{array}$ & $\begin{array}{l}\text { Most students } \\
\text { answered the problem } \\
\text { correctly. There were } \\
\text { two common errors. } \\
11 \% \text { of students } \\
\text { differentiated the } \\
\text { position equation } \\
\text { once to find } \\
\text { acceleration. 7\% of } \\
\text { students integrated } \\
\text { the position equation } \\
\text { twice to find } \\
\text { acceleration. }\end{array}$ \\
\hline & & \\
\hline
\end{tabular}




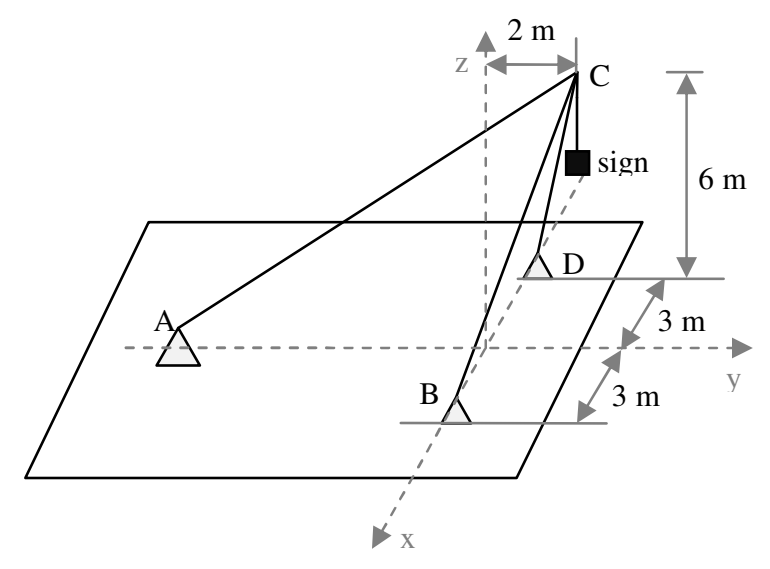

The three questions from the alpha version that were investigated further were changed on the beta version. For example, after further review of the actual homework and exam questions, projection and integrals using trigonometry substitution were removed from the beta instrument as they had not been specific topics asked of the students. Question \#4, which involved derivatives using chain rule, was adjusted slightly. A variable was added, and the new question is shown in Figure 5. Even with the adjustment, students overwhelming still answered the question correctly.

Figure 5. Revised Question on Derivative Using Chain Rule from Beta Instrument

Find the derivative of the following function with respect to $x: \cos \left(x t^{2}+6\right)$

Three areas on the mathematics beta instrument had less than $50 \%$ average of correct answers identified by students, which causes concern. The lowest average received was on threedimensional vector components in question \#4, which was discussed above in Table 5. Students also had a difficult time with integration by substitution. As with the problem on vector components, all of the answer choices received nearly the same weight, which signifies no clear indication on how to solve the problem. The third area causing concern was with two simultaneous equations where one equation contained a parameter. The problem statement specifically stated to solve for $x$ and $y$ in terms of $a$. Problematic is the fact that $25 \%$ of students selected an answer choice solving for $x$ and $a$. Another $16 \%$ of students answered that the problem could not be solved because there are three unknowns and only two equations.

The average response from 368 students on the beta version of the instrument is $54 \%$. This value was considered much lower than the targeted $75 \%$ number. Looking at the results, four students scored a perfect score with two students answering each question on the instrument incorrectly. 


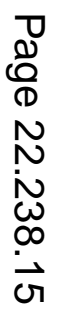




\section{Conclusions}

After administering the instrument and analyzing the results, the authors were able to inform the participating engineering faculty members of the strengths and weaknesses of their students related to the topics covered by the instrument. This knowledge allowed the faculty members to have a better idea of the background of the students in their class. Overall, the students scored lower than expected on the beta instrument. The details on why students performed poorly are outside of the scope of this paper. The instrument identified three significant problem areas where students lack the skills from first-year calculus that are needed for a sophomore-level statics and dynamics course. These areas include three-dimensional vector components, integration by substitution, and simultaneous equations where a parameter was involved.

Properly identifying skills needed from first-year calculus provides a better mechanism for discussing how to meet the needs of students in a sophomore-level statics and dynamics course. By understanding what skills a student enters the course, engineering faculty can make better use of teaching time and evaluate what additional resources might assist learning of the material. For example, several faculty members commented on the additional classroom time that would be spent on three-dimensional vector components after the low numbers of students could correctly identify them. Likewise, the results allow mathematics faculty to be able to determine the utilization of the material they are teaching and be aware of different notations engineering faculty might use for the same concept. The instrument is even useful for students as they are able to improve skills necessary for their success. During the administration of the instrument, students were able to receive a personalized set of results for their review upon request, and approximately $70 \%$ of students asked for this feedback.

Faculty members stated they would be willing to use the instrument again in future classes to determine the first-year mathematics skills their students know upon entering their class. Future work with the instrument will compare the results from the instrument with final success in the course to see the extent of mathematics preparation needed to be successful in engineering. The desire is to be able to alleviate the misalignment between the skills engineering faculty at the sophomore-level felt students should enter their course with and those students actually had obtained.

Questions for future research include studying relationships between student responses on the instrument and performance on examination questions in the course. That is, are there relationships between student knowledge and skills with respect to mathematics at the beginning of the statics and dynamics course and their ability to solve problems in the course?

\section{Bibliography}

1. ABET, Criteria for Accrediting Engineering Programs: Effective for Evaluations During the 2010-2011 Accreditation Cycle. 2010, Baltimore, MD: ABET Engineering Accreditation Commission.

2. Budny, D., Bjedov, G., and LeBold, W. (1997). Assessment of the impact of the freshman engineering courses. 1997 FIE Conference Proceedings.

3. Snyder, V.W., and Meriam, J.L. (1978). The mechanics readiness test - A study of student preparedness for mechanics. Proceedings, ASEE Annual Conference and Exposition. 
4. Snyder, V.W., and Meriam, J.L. (1978b). A study of mathematical preparedness of students: The mechanics readiness test. Journal of Engineering Education. 261-264.

5. Snyder, V.W. (1988). Mechanics readiness test: Revisited. Proceedings, ASEE Annual Conference and Exposition.

6. National Science Board, Undergraduate Science, Mathematics and Engineering Education, NSB 86010. 1986, National Science Foundation: Washington, DC.

7. Ganter, S.L. and Barker, W. (Eds.) (2004). A collective vision: Voices of the partner disciplines, MAA Reports, Washington, DC: Mathematical Association of America.

8. National Science Foundation (1996). Shaping the future: New expectations for undergraduate education in science, mathematics, engineering, and technology. Report of the Advisory Committee for Review of Undergraduate Education, M. George, Chair. Arlington, VA: Author.

9. Armstrong, G., Garner, L., and Wynn, J. (1994). Our experience with two reformed calculus programs. Problems, Resources, and Issues in Mathematics Undergraduate Studies, 4(4), 301-11.

10. Bookman, J. (2000). Program evaluation and undergraduate mathematics renewal: The impact of calculus reform on student performance in subsequent courses. In S.L. Ganter (Ed.), Calculus Renewal: Issues for undergraduate mathematics education in the next decade (pp. 91-102). New York: Kluwer Academic/Plenum Publishers.

11. Jackson, M.B. (1996). Personal correspondence with author about evaluation of calculus reform at Earlham College, from (Ganter 2001).

12. Keith, S.Z. (1995). How do students feel about calculus reform, and how can we tell? UME Trends, 6(6), 6 \& 31.

13. Ganter, Susan L. (Ed.) (2000). Calculus renewal: Issues for undergraduate mathematics education in the next decade. New York: Kluwer Academic/Plenum Publishers.

14. Ganter, Susan L. (2001). Changing calculus: A report on evaluation efforts and national impact from 1988 to 1998. Washington, DC: Mathematical Association of America.

15. Manseur, Z., Ieta, A., and Manseur, R. (2010). Modern mathematics requirements in a developing engineering program. Proceedings, ASEE Annual Conference and Exposition.

16. Cardella, M. (2007). What your engineering students might be learning from their mathematics pre-reqs (beyond integrals and derivatives). Proceedings, Frontiers in Education Conference.

17. Goldfinch, T., Carew, A.L., and McCarthy, T. (2009). A knowledge framework for analysis of engineering mechanics exams. Proceedings of the Research in Engineering Education Symposium.

18. Fadali, M.S., Velasquez-Bryant, N., and Robinson, M. (2004). Work in progress - Is attitude toward mathematics a major obstacle to engineering education? Proceedings, Frontiers in Education Conference.

19. Gomes, G., Bolite, J., and Powell, A. (2010). How and what mathematical content is taught and used by engineer's students at their final course project? Proceedings, ASEE Annual Conference and Exposition.

20. Raubenheimer, D., Ozturk, H., and Duca, A. (2010). Bridging mathematics concepts to engineering contexts: Just-in-time review modules. Proceedings, ASEE Annual Conference and Exposition.

21. Danielson, S.G., and Danielson, E.B. (1992). Problem solving: Improving a critical component of engineering education. In: Creativity: Educating world-class engineers. Proceedings, ASEE Annual Conference and Exposition.

22. Shryock, K.J., Srinivasa, A.R., and Froyd, J.E. (2011). Alignment of Preparation via first-year physics mechanics and calculus courses with expectations for a sophomore statics and dynamics course.

Proceedings, ASEE Annual Conference and Exposition.

23. Craighead, E. and Nemeroff, C. (2000). The Corsini encyclopedia of psychology and behavioral science. Published by John Wiley and Sons. 